Case Report

\title{
Felinosis: the elusive-cat scratch disease
}

\section{S. Arulmozhi, Sithananda Kumar*, Shilpa Divakaran, Susy Sophia Kurian, Mary Kurien}

Department of Otorhinolaryngology, Pondicherry Institute of Medical Sciences, Kalapet, Pondicherry, Tamil Nadu, India

Received: 04 December 2018

Revised: 15 January 2019

Accepted: 17 January 2019

\section{*Correspondence:}

Dr. Sithananda Kumar,

E-mail:dr.jakan@gmail.com

Copyright: (C) the author(s), publisher and licensee Medip Academy. This is an open-access article distributed under the terms of the Creative Commons Attribution Non-Commercial License, which permits unrestricted non-commercial use, distribution, and reproduction in any medium, provided the original work is properly cited.

\section{ABSTRACT}

Cat-scratch disease or felinosis is an infection caused by Bartonella henselae which is characterized by chronic inflammation of the lymph nodes. It is one of the causes of regional, unilateral adenitis in children and adolescents. Axillary lymph nodes followed by cervical, pre-auricular and submandibular lymph nodes are the most common sites of involvement. We report a 14 year old male patient with cat scratch disease in whom the initial clinical manifestations were indistinguishable from those of acute bacterial suppurative lymphadenitis.

Keywords: Cat-scratch disease, Bartonella henselae, Lymphadenopathy

\section{INTRODUCTION}

Cervical lymphadenopathy is more common in children and occurs secondary to bacterial or viral infection of oropharyngeal or cutaneous origin in most occasion. ${ }^{1}$ Tuberculosis, inflammatory disorders and neoplasia are some of the other causes. A detailed history and thorough physical examination together with laboratory tests may be necessary to arrive at a diagnosis. ${ }^{1}$

Cat scratch disease (CSD) also known as felinosis or subacute regional lymphadenitis is a benign infectious disease caused by an intracellular bacterium, Bartonella henselae. $^{2}$ Children are more frequently affected following a scratch or bite of a cat. ${ }^{2}$ Axillary lymph nodes followed by cervical, pre-auricular and submandibular lymph nodes are the most common sites of involvement. ${ }^{1}$ Most patients develop regional lymphadenopathy, preceded by an erythematous papule at the site of inoculation. Healthy people clear infection without treatment, but in $5-14 \%$ the organism disseminate systemically causing pneumonia, encephalitis and hepatitis. $^{3}$ Systemic manifestations are common in immunocompromised patients which may include fever, malaise, anorexia, headache and splenomegaly. ${ }^{3}$

\section{CASE REPORT}

A 14 year old male child presented with a 10 days history of fever and odynophagia. He also gave history of leftsided neck swelling over a period of one week. There was no stridor, no dysphonia. History of weight loss was present. No other relevant history was noted.

Clinical examination revealed a moderately built child, with a unilateral swelling on the left side of the neck. Swelling measured $2.5 \times 2.5 \mathrm{~cm}$ in size which was firm, tender with erythema of the overlying skin and was located at level II. ENT examination showed grade III and grade II enlargement of the left and right tonsils respectively with congestion of the anterior pillars. Indirect laryngoscopy showed no abnormality. Child was admitted in view of suppurative lymphadenitis of left cervical lymph node and was started on IV antibiotics and other supportive measures. Work up was done to rule out tuberculosis.

Investigations revealed an increase in white blood count with marked neutrophilia. ESR was elevated (60 $\mathrm{mm} /$ hour). Other investigations were within normal limit. Blood culture was negative. USG neck was performed 
which demonstrated left sided level II lymphadenopathy with areas of cystic changes suggestive of necrosis. USG guided FNAC was done which showed left cervical swelling with features of suppurative swelling. Sample obtained from FNAC was also subjected to Gene Xpert in which Mycobacterium tuberculosis was not detected. AFB staining was also negative. The swelling persisted and hence a biopsy was done. Biopsy was reported as necrotising granulomatous lesion with suppuration involving lymph nodes and soft tissue in left posterior triangle and level II cervical regions. Cat-scratch disease was suggested as a possibility.

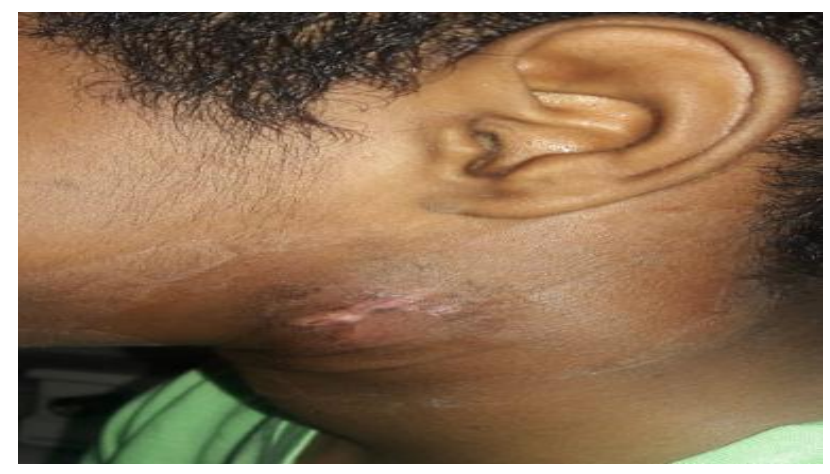

Figure 1: Clinical picture showing left sided neck swelling.

The patient was discharged with oral antibiotics. Careful questioning revealed a history of scratch by the cat on the neck but with no evidence on clinical examination at the site. On follow up, cervical lymphadenopathy noted to have resolved.

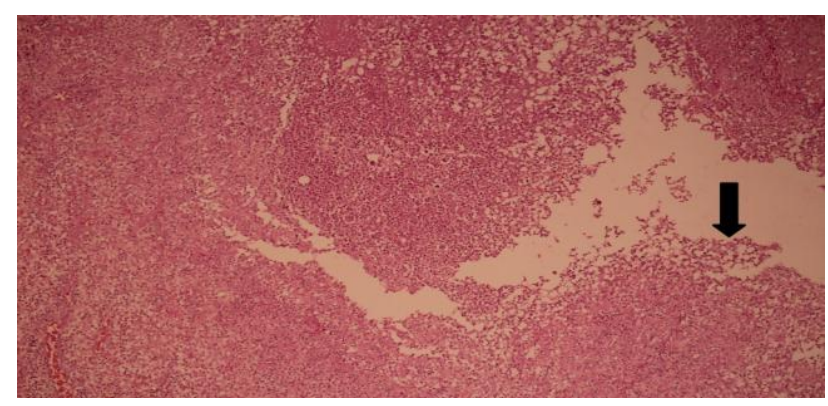

Figure 2: $\mathrm{H}$ and $\mathrm{E}$ 100X magnification showing stellate abscess lined by palisading.

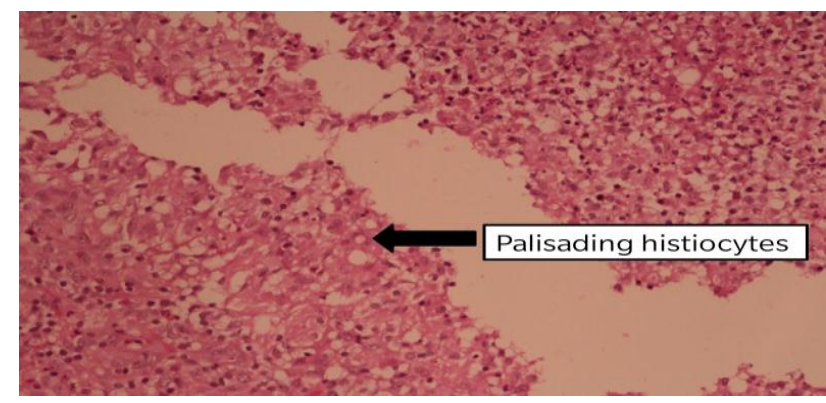

Figure 3: H and E 400X magnification.

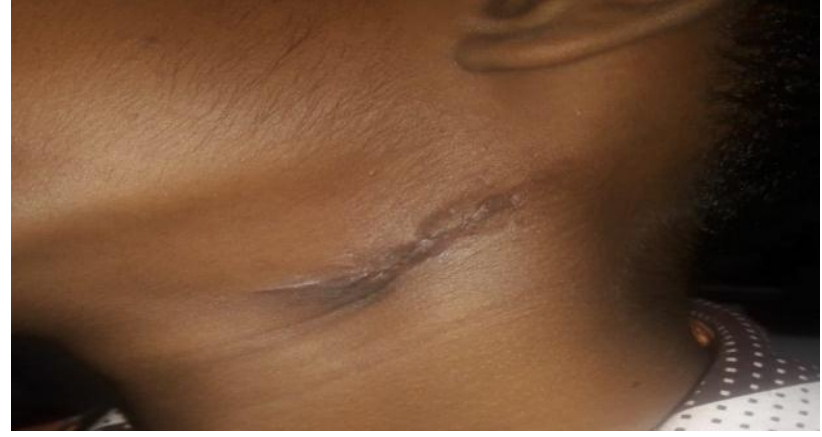

Figure 4: Clinical picture showing reduction in the size of swelling of lymph node after treatment.

\section{DISCUSSION}

Cat scratch disease (CSD) is a bacterial infection caused by small gram-negative bacilli called Bartonella henselae. The bacilli is extremely fastidious and requires special culture media for isolation. ${ }^{4}$ Other conditions caused by Bartonella are bacillary angiomatosis and trench fever which usually affects the immunecompromised. Bartonella henselae is endemic in United States, Europe, Africa, Australia and Japan. Cats are the primary reservoir particularly the kitten stage, and the main vector to cats is the flea as viable $B$. henselae are excreted in cat flea feces. About 24000 people have cat scratch disease each year in United States, $80 \%$ of whom are children. ${ }^{3}$ The disease is also reported as an unrecognised health hazard among veterinarians suggesting it to be more prevalent than previously thought. ${ }^{5}$

Cat scratch disease was first described by Dubre in 1931 although Greer and Keefer published the first case report in 1951.,7 Children are more frequently affected following a scratch or bite of a cat. ${ }^{2}$ Regional lymphadenopathy is considered as the hallmark of CSD. ${ }^{8}$ Axillary lymph nodes followed by cervical, pre-auricular and submandibular lymph nodes are the most common sites of involvement. ${ }^{1}$ The disease is self-limiting with the primary inoculation lesion occurring in atleast $90 \%$ of patients which usually arises within 3-10 days following a cat scratch, bite or lick. The lesion progresses through vesicular, erythematous and papular stage which lasts for 1-3 weeks. Development of regional lymphadenopathy takes 2-4 weeks after inoculation. ${ }^{8}$ The lymph nodes are typically firm and tender early in the disease. The rate of lymph node suppuration varies between $1-48 \%$. ${ }^{9}$ Lymphadenopathy may persist for more than six months in up to $20 \%$ of patients. ${ }^{10}$ One-third of patients have a history of fever greater than 38.3 degree Celsius lasting for one to two weeks which is usually associated with lethargy. Systemic involvement is more common in the immunocompromised patients which includes complications like pneumonia, encephalitis, hepatitis. ${ }^{3}$

Serological and histopathological findings play an important contributory role in reaching the diagnosis of 
Cat scratch disease. The indirect immunofluorescence and enzyme immunoassay tests are reported to have a sensitivity of between $88-95$ percent. ${ }^{11,12}$ However, the role of these tests are not clearly defined. In our case, no serological study for CSD was undertaken as no test was locally available. The histopathologic findings of the lymph nodes involved in CSD may be strongly supportive of the diagnosis. They may vary according to the stage of infection. Lymphoid hyperplasia and arteriolar proliferation are features found in the early stages. This is followed by the appearance of granulomas with central necrosis. ${ }^{8}$ Multiple stellate microabscesses develop later. Warthin-Starry silver impregnation staining may reveal clumps of pleomorphic bacilli in the walls of blood vessels and in the micro-abscesses. The features of all three stages may appear concurrently. ${ }^{13}$

The treatment of cat scratch disease is primarily supportive. Several antibiotics have been used for systemic illness associated with CSD, including gentamicin, rifampicin and ciprofloxacin. The use of antibiotics in CSD with lymphadenopathy without systemic symptoms remains controversial, although some benefit in reduction of size of lymph node has been shown with azithromycin. The role of surgery in the management of CSD is limited. Needle aspiration of a suppurative node is the treatment of choice and may relieve local pain.10 Excision of the involved lymph nodes may be indicated when there is diagnostic uncertainty, upper airway obstruction or for the management of a persistently draining sinus.10 Incision and drainage should be avoided because of the risk of sinus tract formation.

Cat scratch disease can be prevented by flea control measures and washing hands after handling cat or cat feces. Keeping pet cats indoors can prevent infection as they are exposed to fleas outdoors.

\section{CONCLUSION}

Cat scratch disease in reality may be more prevalent than realized. In patients with fever, history of contact with animals to be evaluated and when routine investigations are inconclusive for common granulomatous diseases, cat scratch disease to be considered for effective patient care.

Funding: No funding sources Conflict of interest: None declared

Ethical approval: Not required

\section{REFERENCES}

1. McEwan J, Basha S, Rogers S, Path MRC, Harknesss P. An unusual presentation of cat scratch disease. J Laryngol Otol. 2001;115:826-8.

2. Yasmeen BHN, Jahan RA, Ahmed S, Hussain M, Khan AU, Begum JA, Hoque MM. Cat scratch disease- A case report. Northern International Med College J. 2013;5:316-7.

3. Kalinova K. Felinosis (Cat scratch disease) Diagnosis and treatment. IMAB. 2007;13(1):3-4.

4. Koehler JE, Tappero JW. AIDS commentary: Bacillary angiomatosis and bacillary peliosis in patients infected with human immunodeficiency virus. Clin Infect Dis. 1993;17:612.

5. Chang, Chao-chin, Lee, Chiu-ching, Maruyama, Soichi et al. Cat scratch disease in veterinaryassociated populations and in its cat reservoir in Taiwan. Veterinary Res. 2006;37:565-77.

6. Carithers HA. Cat scratch disease: notes on its history. Ann J Dis Child. 1970;119:200-3.

7. Greer WER, Keefer CS. Cat scratch fever: a disease entity. New Engl J Med. 1951;244:545-8.

8. Spach DH, Koehler JE. Bartonella-associated infections. Infect Dis Clin Noth Am. 1998;12:13755.

9. Daniels WB, MacMurray FG. Cat-scratch disease: Report of one hundred sixty cases. J Am Med Assoc. 1954;154:1247.

10. Carithers HA. Cat-scratch disease: An overview based on a study of 1,200 patients. Am J Dis Child. 1985;139:1124-33.

11. Regnery RL, Olsen JG, Perkins BA, Bibb W. Short reports: Serological response to Rochalimaea henselae antigen in suspected cat-scratch disease. Lancet. 1992;339:1443-5.

12. Dalton MJ, Robinson LE, Cooper J, Regnery RL, Olsen JG, Childs JE. Use of Bartonella antigens for serological diagnosis of cat-scratch disease at a national referral centre. Arch Intern Med. 1995;155:1670-6.

13. Campbell JAH. Cat-scratch disease. Pathol Ann. 1977;12:277-92.

Cite this article as: Arulmozhi S, Kumar S, Divakaran S, Kurian SS, Kurien M. Felinosis: the elusive-cat scratch disease. Int J Otorhinolaryngol Head Neck Surg 2019;5:511-3. 